\title{
Incidence and Association of Body Scheme Disorders in Learning Disabled
}

\author{
Manish Samnani ${ }^{1}$, Pooja Singh ${ }^{2}$ \\ SOCH (Guargaon)
}

\begin{abstract}
Child's representation of his own body is an indispensable element in the formation of his personality. Children first learn their body coordinates e.g. left/right, up/down, and that this knowledge is then applied to letter direction. In other words, the child first develops a body scheme, and then uses the body as a reference for perceiving the difference between letters. Children with learning difficulties have difficulty receiving and processing sensory and perceptual information disrupting their body scheme. This study aims to prove the presence of body scheme disorders in thirty learning disabled children as compared to thirty normal children and in the process helps to develop a standardized assessment measure specifically for learning disabled. The result of the study indicates that there was moderate association of somato-spatial (body-visualization) concepts with reading disorder children.
\end{abstract}

Keywords: Body scheme, Body image, spatial awareness, learning difficulty, finger localization

\section{Introduction}

Researchers and theorists have linked body scheme to the psychosocial, cognitive, and perceptual-motor development in children and therefore, it is a concept that is of concern to paediatric occupational and physical therapists. ${ }^{1}$. Researchers from many different disciplines have studied body awareness and its role in the development of behavior, personality, motor skills, visual-spatial perception, and learning. However, since no consensus exists regarding definition of terms, various terms has been used by different professionals $2,3,4,5$, at times resulting in confusion and perhaps misinterpretation. For example, one of the most commonly used terms is body image. Sometimes this term denotes feelings and attitudes toward the individual's body, but in other cases the term body image is used to refer to one's mental picture of his or her physical body. Despite the variety of terms, concepts, and theories related to the body, most authors agree that the body scheme is an important foundation for several aspects of development. Knowledge of the body is hypothesized to be a pre-requisite for knowledge of the world, for some aspects of memory, and for the understanding of abstract concepts. Kephart, Roach and Kephart, Stapiro, Herman and Mc Monnies hypothesized that the body may be used as a reference for abstract understanding, but they referred to the understanding of letters ${ }^{9}$. These authors all agreed that children generalize from information about the bodies to the discrimination of letters. They theorized that children first learn their body coordinates e.g. left/right, up/ down, and that this knowledge is then applied to letter direction (e.g. b Vs d). In other words, the child first develops a body scheme, and then uses the body as a reference for perceiving the difference between letters. They also hypothesized that some children with excessive reading reversals or difficulty with writing may lack an internal awareness of sidedness (i.e. laterality) and directionality, which are components of the body scheme. Poor directionality (especially left-right orientation) and poor extra corporeal space perception are frequency referred to as "soft signs" of neurological dysfunction ${ }^{10}$. Adams et al (1974) ${ }^{59}$ compared learning disabled fourth graders with a control group for incidence of selected neurological signs. Factors evaluated were eye-hand preferences, balance,stereognosis, graphesthesia, choreoathetosis, finger localization and diadochokinesia. Out of 83 males and 56 female results for finger localization revealed incidence of $9.6 \%$ and $7.1 \%$ in 56 . Mixed laterality was found in $36.1 \%$ of males and $42.9 \%$ of females. Kandt $(1984)^{10}$ regard poor directionality (especially left-right orientation) and poor body image or extracorporeal space perception as subtle or soft neurological signs. Accordingly minor abnormalities are frequently referred to as "soft signs" of neurologic dysfunction and there is a general conclusion that an excess number or degree of such signs occurs with greater prevalence in the group of children with behaviour or learning problems. Wiederholt(1974) ${ }^{45}$ in a historical review on the history of the education of the learning disabled children, identified controversies over definition, territorial rights of respective health and educational professions, and the lack of studies establishing the effectiveness of programs as major problems confronting the field. According to Wiederholt the education and identification of some children as learning disabled is spawned by the results of brain localization studies on adult brain damaged patients and the inference was that children with specific learning problems and normal intelligence had brain damage or brain dysfunction that interfered with learning. Strauss \& Werner(1942) $)^{47}$ and Werner(1948) ${ }^{48}$ studied the characteristics of brain-injured children who were in addition mentally retarded and reported that, like their adult counterparts, these children had perceptual disturbances. They emphasized that children without known brain injury and of normal intelligence did nevertheless possess minimal brain damage. Eminent special educators such as Frostig \& Maslow(1979) ${ }^{51}$ and Cruickshank(1983) ${ }^{52}$ endorsed the position that the knowledge of the status of brain functioning is central to remediation for these children.Others (Keogh,1978; ${ }^{53}$ Mann,1983 ${ }^{54}$ ) argue that neurological considerations are probably relevant for some but not all learning disabilities. According to Kenny et al(1971) ${ }^{55}$ routine medical and neurological examinations tends to be unproductive in evaluating children with learning disability. However studies show the importance of evaluating soft neurological signs in learning disabled children. According to Norton $1972^{56}, 1970^{57}$ these children may have no obvious clinical disorders but they do have perceptual and behavioral 


\section{International Journal of Science and Research (IJSR) \\ ISSN (Online): 2319-7064}

Index Copernicus Value (2015): 78.96 | Impact Factor (2015): 6.391

problems. These characteristics depict the child with soft neurological signs. Recognition of subtle neurologic signs helps develop an appreciation for another component of the substrate upon which the child's behaviour and self-concept are based. If the child has subtle neurologic signs abnormal for age, in the context of learning problem, it is likely that intrinsic factors are playing more of a role than environmental factors. Thus although, the therapist will continue to be alert to adverse environmental circumstances (including parental strife, poor teaching etc) emotional or psychiatric problems, and visual or auditory deficits, he or she will be less likely to assign a primary causal role to one of these factors. In the absence of any signs of dysfunction other than as related to school work, the therapist will wonder more about the possible causal role of interpersonal conflicts, societal and parental expectations, individual learning styles deficiencies of schooling etc. Although the presence of abnormal neurologic signs is more suggestive of primarily a intrinsic problems than an environmental disturbance, the child with the neurologic dysfunction may be more sensitive to ordinary environmental stresses than a child without neurologic dysfunction i.e. the dysfunctional child may have faulty compensatory skills. When Occupational Therapists can demonstrate neurological abnormalities to the parents and/or school personnel, they are often better able to persuade them that reinforcement of the child's attempts will be more beneficial than punishment for being "lazy" "willful" or "stubborn". Thus there is a need to identify the incidence of such disorders; find the nature of such disorder; correlate them to the type of academic problem \& hence make it a focus of intervention. Occupational Therapists must broaden their background to include a capability in the evaluation of these underlying deficits if treatment procedures are to alter the child's central organization and perceptual competency.

\section{Aim of the Study}

The purpose of this study is to determine whether or not body scheme disturbance was a frequent problem of children with learning disabilities and to ascertain if there is any correlation between the nature of body scheme disorder and the type of learning disability.

A standardized and quantified test of the body scheme for such a population apparently did not exist. The development of one became the secondary purpose of the study. The intention is to provide a standardized method of investigating the integrity of the body scheme that would serve as an evaluation instrument to assist the clinical therapist.

Body image scheme appears to have a close relationship to laterality, directionality, and to perceptual-motor development of the preschool child. If body scheme disturbance is a frequent concomitant of learning disability, then every patient with such a diagnosis who is referred to occupational therapy should be tested to determine the presence, absence, or degree of such a disturbance.

\section{Methodology}

Study design- Cross-sectional study design.

Participantants- Total 60 participants between the age group 9 to 14years were included in the study. The experimental group comprised of thirty children with an established diagnosis of learning disorder, referred to occupational therapy department. The other groups comprised of thirty typical children aged 10 to 14 years. Children were considered -typical when not taking medication and not receiving any special services.

\section{Procedure}

Subjects with and without learning disabilities were assessed by all the seven tests of body scheme by MacDonald J.C . These seven tests were- finger localization (examination items 1-5), finger localization (examination items 6-10), right left orientation(examination items 11-16), right-left orientation (examination items 17-22), somato-spatial ability (examinations items 23-27), body-puzzle and draw a men test. Subject placed his hand on the table, palm up with fingers extended and slightly spread. Examiner touched subject's finger with the tip of his index finger. Duration of stimulation was about 1 second. Starting with the index finger the fingers were numbered from one to four and thumb. The pre-final version of the scale was formed having scoring as 0 and 1 . Pilot testing was done on a random sample of the target population. Ten Children were made to attempt on the 7 subtests. They were also asked to comment on the level of difficulty of items to understand and the language of questions. The teachers of the children were also asked to assess the clarity of each item and give necessary suggestions on the items that could be used to improve upon the scale. In order to limit completion and comprehension difficulties, modifications were subsequently made to the test items. Data was collected and sent for statistical analysis. The results were analyzed using STATA software.

\section{Result and Discussion}

Table 1: Demographics of study groups

\begin{tabular}{|c|c|c|c|}
\hline & Pilot Testing & \multicolumn{2}{|c|}{ Field Testing } \\
\hline Diagnosis & $\begin{array}{l}\text { Learning } \\
\text { Disabiliy }\end{array}$ & Normal & $\begin{array}{l}\text { Learning } \\
\text { Disability }\end{array}$ \\
\hline Number (N) & 10 & 25 & 25 \\
\hline Age Range & 9-12years & $\begin{array}{c}\text { 9-13years } \\
\text { Mean : } 10 \\
\text { SD : }(0.91)\end{array}$ & $\begin{array}{c}10-14 \text { years } \\
\text { Mean : } 10.88 \\
\text { SD : }(1.87)\end{array}$ \\
\hline
\end{tabular}

Table 2: Sample characteristics during field testing

\begin{tabular}{|c|c|c|c|c|c|}
\hline & \multicolumn{2}{|c|}{ Male } & \multicolumn{2}{c|}{ Female } & \\
\hline Diagnosis & N & $\%$ & N & $\%$ & Total \\
\hline Normal & 20 & $80 \%$ & 5 & $20 \%$ & 25 \\
\hline Learning Disability & 16 & $64 \%$ & 9 & $36 \%$ & 25 \\
\hline
\end{tabular}

Table 3: Sample characteristics of learning disability group

\begin{tabular}{|c|c|c|c|c|c|c|}
\hline & \multicolumn{2}{|c|}{ MALE } & \multicolumn{2}{|c|}{ FEMALE } & & \\
\hline Type & N & $\%$ & N & $\%$ & Total & $\%$ \\
\hline Reading & 6 & $24 \%$ & 3 & $12 \%$ & 9 & $36 \%$ \\
\hline Writing & 6 & $24 \%$ & 4 & $16 \%$ & 10 & $40 \%$ \\
\hline Mathematics & 4 & $16 \%$ & 2 & $8 \%$ & 6 & $24 \%$ \\
\hline
\end{tabular}




\section{International Journal of Science and Research (IJSR) \\ ISSN (Online): 2319-7064 \\ Index Copernicus Value (2015): 78.96 | Impact Factor (2015): 6.391}

The cut off mark was calculated for each subtest by calculating the sensitivity and specificity for every possible score on each subtest and on full scale. The score having the highest possible sensitivity and specificity was chosen.

Table 4: Detailed report of Sensitivity and Specificity for finger recognition (scores of subtest $1+$ subtest 2 )

\begin{tabular}{|c|c|c|c|}
\hline Cut point & Sensitivity & Specificity & Correctly classified \\
\hline$(>=3)$. & $100.00 \%$ & $0.00 \%$ & $50.00 \%$. \\
\hline$(>=7)$ & $100.00 \%$ & $4.00 \%$ & $52.00 \%$ \\
\hline$(>=8)$ & $96.00 \%$ & $8.00 \%$ & $52.00 \%$ \\
\hline$(>=9)$ & $96.00 \%$ & $12.00 \%$ & $54.00 \%$ \\
\hline$(>=10)$ & $88.00 \%$ & $20.00 \%$ & $54.00 \%$ \\
\hline$(>10)$ & $0.00 \%$ & $100.00 \%$ & $50.00 \%$ \\
\hline
\end{tabular}

Table 5: Detailed report of Sensitivity and Specificity for right-left discrimination (scores of subtest $1+$ subtest 2)

\begin{tabular}{|c|c|c|c|}
\hline $\begin{array}{c}\text { Cut } \\
\text { point }\end{array}$ & Sensitivity & Specificity & $\begin{array}{c}\text { Correctly } \\
\text { Classified }\end{array}$ \\
\hline $\begin{array}{c}(>=0 \\
)\end{array}$ & $100.00 \%$ & $0.00 \%$ & $50.00 \%$ \\
\hline $\begin{array}{c}(>=7 \\
)\end{array}$ & $100.00 \%$ & $4.00 \%$ & $52.00 \%$ \\
\hline $\begin{array}{c}(>= \\
11)\end{array}$ & $100.00 \%$ & $12.00 \%$ & $56.00 \%$ \\
\hline $\begin{array}{c}(>= \\
12)\end{array}$ & $96.00 \%$ & $20.00 \%$ & $58.00 \%$ \\
\hline $\begin{array}{c}(> \\
12)\end{array}$ & $0.00 \%$ & $100.00 \%$ & $50.00 \%$ \\
\hline
\end{tabular}

Table 6: Detailed report of Sensitivity and Specificity for Subtest 5

\begin{tabular}{|l|l|l|l|}
\hline Cut point & Sensitivity & Specificity & Correctly Classified \\
\hline$(>=1)$ & $100.00 \%$ & $0.00 \%$ & $50.00 \%$ \\
\hline$(>=2)$ & $96.00 \%$ & $4.00 \%$ & $50.00 \%$ \\
\hline$(>=3)$ & $88.00 \%$ & $12.00 \%$ & $50.00 \%$ \\
\hline$(>=4)$ & $80.00 \%$ & $24.00 \%$ & $52.00 \%$ \\
\hline$(>=5)$ & $60.00 \%$ & $52.00 \%$ & $56.00 \%$ \\
\hline$(>5)$ & $0.00 \%$ & $100.00 \%$ & $50.00 \%$ \\
\hline
\end{tabular}

Table 7: Detailed report of Sensitivity and Specificity for Subtest 6

\begin{tabular}{|c|c|c|c|}
\hline $\begin{array}{c}\text { Cut } \\
\text { point }\end{array}$ & Sensitivity & Specificity & $\begin{array}{c}\text { Correctly } \\
\text { Classified }\end{array}$ \\
\hline$(>=0)$ & $100.00 \%$ & $0.00 \%$ & $50.00 \%$ \\
\hline$(>=3)$ & $100.00 \%$ & $4.00 \%$ & $52.00 \%$ \\
\hline$(>=5)$ & $100.00 \%$ & $8.00 \%$ & $54.00 \%$ \\
\hline$(>5)$ & $0.00 \%$ & $100.00 \%$ & $50.00 \%$ \\
\hline
\end{tabular}

Table 8: Detailed report of Sensitivity and Specificity for Subtest 7

\begin{tabular}{|c|c|c|c|}
\hline Cut point & Sensitivity & Specificity & Correctly Classified \\
\hline$(>=1)$ & $100.00 \%$ & $0.00 \%$ & $50.00 \%$ \\
\hline$(>=7)$ & $100.00 \%$ & $4.00 \%$ & $52.00 \%$ \\
\hline$(>=8)$ & $100.00 \%$ & $8.00 \%$ & $54.00 \%$ \\
\hline$(>=9)$ & $100.00 \%$ & $12.00 \%$ & $56.00 \%$ \\
\hline$(>=10)$ & $100.00 \%$ & $20.00 \%$ & $60.00 \%$ \\
\hline$(>10)$ & $0.00 \%$ & $100.00 \%$ & $50.00 \%$ \\
\hline
\end{tabular}

Table 9: Detailed report of Sensitivity and Specificity for Total score

\begin{tabular}{|c|c|c|c|}
\hline Cut point & Sensitivity & Specificity & Correctly Classified \\
\hline$(>=15)$ & $100.00 \%$ & $0.00 \%$ & $50.00 \%$ \\
\hline$(>=25)$ & $100.00 \%$ & $4.00 \%$ & $52.00 \%$ \\
\hline$(>=36)$ & $100.00 \%$ & $8.00 \%$ & $54.00 \%$ \\
\hline$(>=37)$ & $100.00 \%$ & $12.00 \%$ & $56.00 \%$ \\
\hline$(>=38)$ & $100.00 \%$ & $16.00 \%$ & $58.00 \%$ \\
\hline$(>=39)$ & $96.00 \%$ & $32.00 \%$ & $64.00 \%$ \\
\hline$(>=40)$ & $84.00 \%$ & $40.00 \%$ & $62.00 \%$ \\
\hline$(>=41)$ & $68.00 \%$ & $44.00 \%$ & $56.00 \%$ \\
\hline$(>=42)$ & $52.00 \%$ & $64.00 \%$ & $58.00 \%$ \\
\hline$(>42)$ & $0.00 \%$ & $100.00 \%$ & $50.00 \%$ \\
\hline
\end{tabular}

Study of the analysis reveals the following cut off points for each subtest and also for total score at the maximum possible sensitivity and specificity.

Table 10: Table showing Cut-off scores for different subtests and total score

\begin{tabular}{|c|c|c|c|}
\hline Subtest number & Min. Score & Max. Score & Cut point \\
\hline 1 & 0 & 5 & 5 \\
\hline 2 & 0 & 5 & 5 \\
\hline 3 & 0 & 6 & 6 \\
\hline 4 & 0 & 6 & 6 \\
\hline 5 & 0 & 5 & 4 \\
\hline 6 & 0 & 5 & 5 \\
\hline 7 & 0 & 10 & 10 \\
\hline Total Score & 0 & 42 & 39 \\
\hline
\end{tabular}

Table 11: Descriptive statistics of above cut-off scorers on full scale

\begin{tabular}{|c|c|c|c|c|c|c|}
\hline Diagnosis & Male & $\%$ & Female & $\%$ & Total & $\%$ \\
\hline Normal & 19 & $76 \%$ & 5 & $20 \%$ & 24 & $96 \%$ \\
\hline Learning Disability & 11 & $44 \%$ & 6 & $24 \%$ & 17 & $68 \%$ \\
\hline
\end{tabular}

Table 12: Descriptive statistics of below cut-off scorers on full scale

\begin{tabular}{|c|c|c|c|c|c|c|}
\hline Diagnosis & Male & $\%$ & Female & $\%$ & Total & $\%$ \\
\hline Normal & 1 & $4 \%$ & 0 & 0 & 1 & $4 \%$ \\
\hline Learning Disability & 5 & $20 \%$ & 3 & $12 \%$ & 8 & $32 \%$ \\
\hline
\end{tabular}

The incidence of body scheme disorders as calculated by those scoring below cut-off of 39 on the over-all scale is thus $32 \%$ (8 out of 25 ). $4 \%$ (1 out of 25 ) of normal subjects also scored below cut-off.

Table 13: Descriptive statistics of above cut-off scorers on full scale of learning disability group

\begin{tabular}{|c|c|c|c|c|c|c|}
\hline Learning Disability & Male & $\%$ & Female & $\%$ & Total & $\%$ \\
\hline Reading & 3 & $12 \%$ & 1 & $4 \%$ & 4 & $16 \%$ \\
\hline Writing & 5 & $20 \%$ & 3 & $12 \%$ & 8 & $32 \%$ \\
\hline Mathematics & 3 & $12 \%$ & 2 & $8 \%$ & 5 & $20 \%$ \\
\hline
\end{tabular}

Table 14: Descriptive statistics of below cut-off scorers on full scale of learning disability group

\begin{tabular}{|c|c|c|c|c|c|c|}
\hline Learning Disability & Male & $\%$ & Female & $\%$ & Total & $\%$ \\
\hline Reading & 3 & $12 \%$ & 2 & $8 \%$ & 5 & $20 \%$ \\
\hline Writing & 1 & $4 \%$ & 1 & $4 \%$ & 2 & $8 \%$ \\
\hline Mathematics & 1 & $4 \%$ & 0 & 0 & 1 & $4 \%$ \\
\hline
\end{tabular}




\section{International Journal of Science and Research (IJSR) ISSN (Online): 2319-7064 \\ Index Copernicus Value (2015): 78.96 | Impact Factor (2015): 6.391}

Table 15: Case summaries of normal and learning disability groups on full scale

\begin{tabular}{|c|c|c|c|c|c|c|c|c|}
\hline & N & $\begin{array}{c}\text { Min } \\
\text { Score }\end{array}$ & $\begin{array}{c}\text { Max } \\
\text { Score }\end{array}$ & Range & Mean & SD & SEM & $\begin{array}{c}\text { p value } \\
\text { (t-test) }\end{array}$ \\
\hline Normal & 25 & 38 & 42 & 4 & 41 & 1.25 & 0.25 & 0.03 \\
\hline $\begin{array}{c}\text { Learning } \\
\text { Disability }\end{array}$ & 25 & 15 & 42 & 27 & 38.64 & 1.21 & 6.08 & \\
\hline
\end{tabular}

Table 16: Case summaries of learning disability group on full scale

\begin{tabular}{|c|l|l|l|l|l|l|}
\hline Learning Disability & Male & $\%$ & Female & $\%$ & Total & $\%$ \\
\hline Reading & 9 & 15 & 42 & 27 & 34.14 & 10.22 \\
\hline Writing & 10 & 36 & 42 & 6 & 40.2 & 2.20 \\
\hline Mathematics & 6 & 38 & 42 & 4 & 41.0 & 1.55 \\
\hline
\end{tabular}

Table 17: Descriptive statistics of above cut-off scorers on subtest 1

\begin{tabular}{|c|c|c|c|c|c|c|}
\hline Diagnosis & Male & $\%$ & Female & $\%$ & Total & $\%$ \\
\hline Normal & 17 & $68 \%$ & 5 & $20 \%$ & 22 & $88 \%$ \\
\hline Learning Disability & 14 & $52 \%$ & 6 & $28 \%$ & 20 & $80 \%$ \\
\hline
\end{tabular}

Table 18: Descriptive statistics of below cut-off scorers on subtest 1

\begin{tabular}{|c|c|c|c|c|c|c|}
\hline Diagnosis & Male & $\%$ & Female & $\%$ & Total & $\%$ \\
\hline Normal & 3 & $12 \%$ & 0 & 0 & 3 & $12 \%$ \\
\hline Learning Disability & 2 & $8 \%$ & 3 & $12 \%$ & 5 & $20 \%$ \\
\hline
\end{tabular}

The incidence of finger agnosia as calculated by those scoring below cut-off of 5 in subtest 1 is thus $20 \%$ (5 out of 25). $12 \%$ (3 out of 25) of normal subjects also scored below cut-off.

Table 19: Descriptive statistics of above cut-off scorers on subtest 1 of learning disability group

\begin{tabular}{|c|c|c|c|c|c|c|}
\hline Learning Disability & Male & $\%$ & Female & $\%$ & Total & $\%$ \\
\hline Reading & 5 & $20 \%$ & 1 & $4 \%$ & 6 & $24 \%$ \\
\hline Writing & 5 & $20 \%$ & 3 & $12 \%$ & 8 & $32 \%$ \\
\hline Mathematics & 4 & $16 \%$ & 2 & $8 \%$ & 6 & $24 \%$ \\
\hline
\end{tabular}

Table 20: Descriptive statistics of below cut-off scorers on subtest 1 of learning disability group

\begin{tabular}{|c|c|c|c|c|c|c|}
\hline Learning Disability & Male & $\%$ & Female & $\%$ & Total & $\%$ \\
\hline Reading & 1 & $4 \%$ & 2 & $8 \%$ & 3 & $12 \%$ \\
\hline Writing & 1 & $4 \%$ & 1 & $4 \%$ & 2 & $8 \%$ \\
\hline Mathematics & 0 & 0 & 0 & 0 & 0 & 0 \\
\hline
\end{tabular}

\section{Test validation}

The construct and content validity of the test was supported by the fact that the test procedures were derived from those suggested in well established neurological and Occupational Therapy literature regarding testing of the constructs of body scheme $^{13,17,29,33-38,40,41}$.

\section{Pilot testing}

In order to limit completion and comprehension difficulties, modifications were subsequently made to the test items which included changing the name of the fingers in the hand chart from first finger, second finger, third finger, fourth finger \& instead naming them as finger one, finger two, finger three, finger four respectively in subtest one.
In subtest 4 the names of the body parts in the practice questions arm, cheek were difficult to understand due to limited English vocabulary at that age.

Thus in the test questions of subtest 4 the body parts cheek, foot, arm were changed and instead eye, shoe, shoulder were used respectively.

In subtest 5 the names of the body parts in the practice questions elbow, foot, ankle were changed and instead hand, shoe, leg were used respectively.

In the same subtest, the first test item "Your mouth is below your chin" was changed and instead "Your mouth is above your eyes" was used to avoid use of the term "chin" which was hard to understand by children of that age.

The second test item "Your eyes are above your forehead" was changed instead "Your eyes are above your head" was used.

The third test item "Your knees are below your hips" was changed instead "Your legs are below your stomach" was used.

The fourth test item "Your hands are at the end of your arms" was changed and instead "Your shoes are after your legs" was used.

The fifth test item "You have one chin, one nose, and one mouth" was modified into "You have one nose, one mouth, and two eyes".

\section{Field testing}

Field testing was done on the final version of the scale. Teachers were asked to categorize the learning disability subjects into one of the three groups of reading, writing, arithmetic disorder. 25 children could be placed into one of the three groups. It was difficult for the teachers \& educators to categorize others because they had learning problems of mixed nature, rather than in predominantly one area. Although DSM-IV differentiates learning disabled into three diagnostic types but the experience of this study states that mixed kind of learning problems are much more common. No formal assessment was used by the teachers for categorizing the children.

Cut-off score were calculated for each of the seven subtests with reasonable sensitivity and specificity. In the majority of the tests, full score was the only acceptable score as normal performance. However subtest 5 which included body visualization questions of true/false nature did not had a full score as cut-off. The cut-off for full scale was found to be 39. Similar cut-off was reported by MacDonald ${ }^{34}$, when comparing the scores of neurologically impaired having one or more cerebral vascular accidents and neurologically nonimpaired groups.

Since interest of the study was centered on the performances of individuals rather than on statistically determined group differences, an analysis of the proportion of subjects in each group who showed defective performance was made. 


\section{International Journal of Science and Research (IJSR) \\ ISSN (Online): 2319-7064}

Index Copernicus Value (2015): 78.96 | Impact Factor (2015): 6.391

Based on the cut off score, incidence of body scheme disorders was calculated. The overall incidence i.e. those who scored below cut-off on full scale was found to be $32 \%$.

Incidence of finger agnosia (those scoring below cut-off in subtests 1 and 2) was found to be $28 \%$. Incidence of rightleft indiscrimination (those scoring below cut-off in subtests 3 and 4 ) was found to be $28 \%$. Body visualization, (somatospatial) concept deficits (as tested by those scoring below cut-off in subtests 5, 6 and 7) was found in 52\%.

Benton (1955) ${ }^{58}$ reported an incidence of finger localization of $24.5 \%$. The incidence results for right-left discrimination were $18.2 \%$.

Adams (1974) $)^{59}$ found incidence of poor finger-localization as one of the soft neurological sign, in $9.6 \%$ males \& $7.1 \%$ females and mixed laterality in $36.1 \%$ males \& $42.9 \%$ females.

The association with different learning disorders as calculated by those scoring below cut-off for subtests 1 to 7 in the three different groups of reading, writing, arithmetic disorder was calculated. In the reading group an association of less than 35\% (33\%, 11\%, 22\%, 33\%, 55\%, 11\% \& 33\% with subtests 1 to 7 respectively) was found except for subtest 5 which was $55 \%$. Association results indicate that there was moderate association of somato-spatial (bodyvisualisaion) concepts with reading disorder children. However children in the same group scored below cut-off on other tests also. Thus scores of a particular subtest cannot be said to be significantly associated with the reading group.

Similar analysis revealed an association of less than equal to $20 \%$ in writing group $(20 \%, 10 \%, 10 \%, 20 \%, 10 \%, 10 \% \&$ $10 \%$ respectively). Thus the results cannot draw a clear association.

Analysis of arithmetic disorder children revealed that only 1 child out of 6 tested (16\%) made error on the draw-a-man test only. Thus there was a moderate association between the two but the strength of association is weak due to a very small sample size.

Strauss \& Werner $(1938)^{42}$ claimed an obvious relation between deficiency in the finger schema and deficiency in arithmetic achievement while Benton \& Hutcheon (1951) ${ }^{43}$ refuted the hypothesis that finger localizing ability and arithmetic achievement are significantly associated with each other, in normal as well as mental deficiency children. They also indicated that there was no relationship between arithmetic ability and right-left discrimination. The findings of the present study are in accordance with these results.

This study did not find association with any particular kind of body scheme deficit in the children with agraphia as well. This result is not in accordance with PeBenito (1988) ${ }^{60}$ who reported Gerstmann's Syndrome in 5 out of 10 learning disabled children tested and suggested that Developmental Gerstmann Syndrome may not be as rare as previously thought and may often be unrecognized.

\section{Test-retest}

The tests were also assessed for their retest value by administering them to 10 children of the same sample after 1.5 months of initial testing. It was to done to eliminate contamination of the retest results due to learning of the test items. Overall value of retest was 0.99 which is near perfect agreement showing that test had good test-retest reliability. MacDonald also found a reliability coefficient $r=0.98 .^{34}$ Information from the literature suggests inter-rater reliability of some individual tests ranges from $0.84^{14}-0.98^{40}$.

\section{Limitations}

The study was concerned with developing an instrument to assess body scheme ability and using it to calculate incidence of body scheme disorders. Specific limitations of the study were:

1) 5 out of seven tests were interview based and hence the assessment cannot be performed on those children who had comprehension, vocabulary and language problems. This limits generalizability of the scale for the entire learning disability population.

2) The medium of language used is limited to English; hence students of any other language medium school cannot be tested.

Small sample size of 30 limits generalizability.

Accurate matching of mental and chronological age was not done which limits comparison accuracy.

\section{Recommendations}

The findings of the study lead to the following broad recommendations:

1) Functional test items should be included to further develop the assessment scale.

2) Effect of Occupational Therapy intervention should be seen on body scheme ability using this scale as an outcome measure.

3) Body scheme is a multidimensional concept. This scale uses the cognitive and perceptual-motor domains. Further studies should include affective domains as well.

\section{References}

[1] American Occupational Therapy Association (1994) Uniform Terminology for Occupational Therapy-third edition. American Journal of Occupational Therapy. 48:1047-1054

[2] Miller KD (1991) Body Image Therapy. Nursing Clinics of North America. 26:727-736

[3] Mock V (1993) Body Image in Women Treated for Breast Cancer. Nursing Research. 42:153-157

[4] Hopkins HS, Smith HD, (1993) eds. Willard and Spackman's Occupational Therapy. $8^{\text {th }}$ ed. San Jose, CA: J.B. Lippincott Company.

[5] Sirigu A, Grafman J et.al. (1991) Multiple Representations contribute to Body Knowledge Processing. Evidence from a case of Autopagnosia. Brain. 114:629-642. 


\section{International Journal of Science and Research (IJSR) \\ ISSN (Online): 2319-7064}

Index Copernicus Value (2015): 78.96 | Impact Factor (2015): 6.391

[6] Culp RE, Packard VN, Humphry R (1980) Sensory Motor versus Cognitive-Perceptual Training Effects on the Body Concept of Preschoolers. American Journal of Occupational Therapy. 34:259-262.

[7] Ayres AJ (1961) The Development of the Body Scheme in Children. American Journal of Occupational Therapy. 15:99-128.

[8] Warah A (1989) Body Image Disturbance in Anorexia Nervosa: Beyond Body Image. Canadian Journal of Psychiatry. 34:898-905.

[9] Mitchell AW (1997) Body Scheme Theory. Physical and Occupational Therapy in Pediatrics. 17(4):5-23.

[10] Kandt R.S. (1984) Neurologic Examination of Children with Learning Disorders, Pediatric Clinics of North America, 31(2), 294-315.

[11] Lautenbacher S, Roscher S et.al. (1993) Theoretical and empirical considerations on the relation between "body image", body scheme, and somatosensation. Journal of Psychosomatic Research. 37:447-454.

[12] Quintana LA (1989) Cognitive and perceptual evaluation and treatment, In: C. Trombly,ed. Occupational Therapy for physical dysfunction, Baltimore: Williams and Wilkins.

[13] Zoltan B, Siev E, Freishtat B (1990) The adult stroke patient: a manual for evaluation and treatment of perceptual and cognitive dysfunction, New York: McGraw Hill.

[14] Pedretti LW, Zoltan B (1990) Occupational Therapy: practice skills for physical dysfunction, 3rd ed. Baltimore, Mosby.

[15] Corbett A, Shah S, (1996) Body Scheme Disorders following Stroke and Assessment in Occupational Therapy, British Journal of Occupational Therapy, 59(7), 325-329.

[16] Shontz F (1955) Body concept disturbances of patients with hemiplegia. Journal of Clinical Psychology, 11,293-295.

[17] Zoltan B, Jabri J, Ryckman DLM, Panikoff LB (1983) Perceptual Motor Evaluation for Head Injured and other Neurologically Impaired Adults. California: Occupational Therapy Department, Santa Clara Valley Medical Center.

[18] Benton A (1961) The Fiction of The Gerstmann Syndrome. Journal of Neurology, Neurosurgery and Psychiatry, 24,176-181.

[19] Poeck K, Orgass B (1971) The concept of the body schema: a critical review and some experimental results. Cortex. 7, 254-277.

[20] Lacey JH, Birtchnell SA (1986) Body Image and Its Disturbances, Journal of Psychosomatic Research., 30, 623-631.

[21] Trimble M (1988) Body Image and The Temporal Lobes. British Journal of Psychiatry, 153,12-14.

[22] Van Deusen J (1993) Body image and perceptual dysfunction in adults. Philadelphia, Saunders.

[23] Ayres AJ (1972) Sensory Integration and Learning Disorders, California: Western Psychological Services.

[24] Cumming WJK (1988) The Neurobiology of Body Schema, British Journal of Psychiatry, 153, 7-11.

[25] Van Deusen J, Fox H, Harlowe D (1984) Construct Validation of Occupational Therapy Measures used in CVA Evaluation: A Beginning. American Journal of Occupational Therapy, 38,101-106.
[26] Hodges C, Bender L (1994) Phantom Pain: A Critical Review of the Proposed Mechanisms. British Journal Occupational Therapy

[27] Robinson RO, Lippold T, Land R (1986) Body Schema: Does It Depend on Bodily Derived Sensations? Developmental Medicine \& Child Neurology, 28, 49-52

[28] Lynch J (1980) The Functional Organization of the Posterior Parietal Association Cortex. Behavioral and Brain Sciences, 3, 485-534.

[29] Frederiks JAM (1985) Disorders of the Body Schema. In: P.Vinken, G. Bruyn, eds. The Handbook of Clinical Neurology. Amsterdam: Elsevier, 100-143.

[30] Snaith P (1992) Body Image Disorders, Psychotherapy and Psychosomatics, 58, 119-124.

[31] Sauguet J, Benton AL, Hecaen H (1971) Disturbances of the Body Schema in Relation to Language Impairment and Hemispheric Locus of Lesion. Journal of Neurology, Neurosurgery \& Psychiatry 34, 496-501.

[32] Maloney M, Payne L (1969) Validity of the Draw-aPerson Test as a Measure of Body Image. Perceptual and Motor Skills, 29, 119-122.

[33] Taylor M (1968) Analysis of Dysfunction in Left Hemiplegia following Stroke. American Journal of Occupational Therapy, 22, 512-520.

[34] MacDonald JC (1960) An Investigation of Body Scheme in Adults with Cerebral Vascular Accidents. American Journal of Occupational Therapy, 14, 75-79.

[35] Whiting s, Lincoln N, Bhavnani G, Cockburn J (1985) The Rivermead Perceptual Assessment Battery, Windson; NFER-Nelson.

[36] Boone D, Landes B (1968) Left/Right Discrimination in Hemiplegic Patients. Archives of Physical Medicine and Rehabilitation, 49, 533-537.

[37] Shah S, Cooper B, Maas F (1993) Performance on Perceptual Tasks by Neurologically Impaired Adults Using the Dominant Right Hand, Australian Journal of Occupational Therapy, 40, 165-174.

[38] Feigenson JS, Polkow L, Keegan N (1980) Burke Perceptual Profile, New York: American Neurological Foundation.

[39] Harlowe D,Van Deusen J (1984) Construct Validation of the St. Mary's CVA Evaluation: Perceptual Measures, American Journal of Occupational Therapy, 38, 184-186.

[40] Matthey S, Donnelly SM, Hextell DL (1993) The Clinical Usefulness of The Rivermead Perceptual Assessment Battery. British Journal of Occupational Therapy, 56, 365-370.

[41] Benton A (1955), Development of Finger Localization Capacity in School Children, Child development, 26(4), 225-230.

[42] Strauss AA, Werner H, (1938), Deficiency in the Finger Schema in relation to arithmetic disability (finger agnosia and acalculia), American Journal of Orthopsychiatry, 8, 719-725.

[43] Benton AL, Hutcheon JF et al (1951), Arithmetic Ability, Finger Localization Capacity and Right-Left Discrimination in Normal and Defective Children, American Journal of Orthopsychiatry, 21, 756-766.

[44] Swanson R. \& Benton AL (1955), Some aspects of the genetic development of right-left discrimination, Child Development, 26, 123-133. 
[45] Vellutino F. et al (1977), Has the Perceptual Deficit Hypothesis Led Us Astray? Journal of Learning Disabilities, 10(6), 375.

[46] Goldstein K (1939), The Organism, New York, 1939, American Book Co.

[47] Strauss AA, \& Werner H (1942), Disorders of Conceptual Thinking in the Brain-Injured Child, Journal Nervous Mental Diseases, 96,153.

[48] Werner H (1948), Comparative Psychology of Mental Development, New York, International Universities Press.

[49] Strauss AA, \& Lehtinen LE (1947), Psychopathology and Education of the Brain-Injured Child, New York, Grune \& Stratton, Inc.

[50] Strauss AA, \& Kephart NC (1955), Psychopathology and Education of the Brain-Injured Child, New York, Grune \& Stratton, Inc.

[51] Frostig M \& Maslow P (1979), Neuropsychological Contributions to Education, Journal of Learning Disabilities, 12(8), 538.

[52] Cruickshank W (1983), Learning Disabilities: A Neuropsychological Dysfunction, Journal Learning Disabilities, 16(1), 27.

[53] Keogh BK (1978), Marker Variables: A search for Compatibility and Generalizability in the Field of Learning Disabilities, Learning Disability Quarterly 3(3), 8.

[54] Mann L et al (1983), LD or not LD, That was the Question: A Retrospective Analysis of Child Service Demonstration Centers in Compliance with the Federal Definition of Learning Disabilities, Journal of Learning Disabilities, 16(1), 14.

[55] Kenny T.J. et al (1971) Characteristics of children referred because of hyperactivity. Journal of Pediatrics, 79:618-622.

[56] Norton Y (1972) Minimal Cerebral Dysfunction. American Journal of Occupational Therapy 26(3): 135-146.

[57] Norton Y (1970) Structuro-Functional Development leading towards early Cognito-Perceptual Behaviour. American Journal of Occupational Therapy 24(1):3443.

[58] Benton LA (1955) Right-Left Discrimination and Finger Localization in Defective Children. Archives of Neurology \& Psychiatry. 583-58

[59] Adams RM, Kocsis JJ, Estes RE (1974) Soft Neurological Signs in Learning Disabled Children and Controls. American Journal of Diseases in Childhood 128, 614-618.

[60] PeBenito R, Fisch CB, Fisch ML (1988) Developmental Gerstmann's Syndrome. Archives of Neurology 45:977-982.

[61] www.kuleuven.ac.be/research/researchdatabas e/project/3M03/3M030433.htm 